CLINICAL STUDY

\title{
Metabolic decompensation in children with type 1 diabetes mellitus associated with increased serum levels of the soluble leptin receptor
}

\author{
J Kratzsch ${ }^{1, *}$ I Knerr ${ }^{3, *}$, A Galler ${ }^{2}$, T Kapellen ${ }^{2}$, K Raile ${ }^{2}$, A Körner ${ }^{2}$, J Thiery ${ }^{1}$, J Dötsch ${ }^{3}$ and W Kiess ${ }^{2}$ \\ ${ }^{1}$ Institute of Laboratory Medicine, Clinical Chemistry and Molecular Diagnostics and ${ }^{2}$ Hospital for Children and Adolescents, University of Leipzig, \\ Paul-List-Str, 13-15, D-04103 Leipzig, Germany and ${ }^{3}$ Children's Hospital, University of Erlangen, Erlangen, Germany
}

(Correspondence should be addressed to J Kratzsch; Email: kraj@medizin.uni-leipzig.de)

*(J Kratzsch and I Knerr contributed equally to this work)

\begin{abstract}
Objective: Type 1 diabetes mellitus (T1DM) leads to increased serum levels of the soluble leptin receptor (sOB-R) by an as yet unknown cellular mechanism. The aim of our study was to investigate potential metabolic factors that may be associated with the induction of the sOB-R release from its membrane receptor.

Materials and methods: Twenty-five children (aged between 1.5 and 17.0 years) were studied at the onset of T1DM. Blood samples were collected before $(n=25)$, during the first $18 \mathrm{~h}$ (mean \pm s.D. $11.1 \pm$ $4.3 \mathrm{~h}, n=16)$ and $92 \mathrm{~h}(47.5 \pm 22.5 \mathrm{~h} ; n=14)$ after beginning insulin therapy. Serum sOB-R and leptin levels were determined by in-house immunoassays.

Results: The sOBR-level and the molar sOB-R/leptin ratio were significantly higher before than after starting insulin treatment $(P<0.05)$. In contrast, leptin levels were significantly lower $(P<0.05)$ before insulin therapy. The correlation between sOB-R and blood glucose $(r=0.49 ; P<0.05)$, as well as sOB-R with parameters of ketoacidosis, such as $\mathrm{pH}(r=-0.72)$, base excess $(r=-0.70)$, and bicarbonate $(r=-0.69)(P<0.0001)$ at diagnosis of T1DM remained significant during the first $18 \mathrm{~h}$ of insulin treatment. Multiple regression analysis revealed that base excess predicted $41.0 \%$ $(P<0.001)$, age $16.4 \%(P<0.05)$, and height SDS 13.9\% $(P<0.01)$ of the sOB-R variance. Conclusions: Metabolic decompensation in children with new onset T1DM is associated with dramatic changes of the leptin axis; serum levels of sOB-R are elevated and of leptin are reduced. The molar excess of sOB-R over leptin (median 11.3) in this condition may contribute to leptin insensitivity. Upregulation of the soluble leptin receptor appears to be a basic mechanism to compensate for intracellular substrate deficiency and energy-deprivation state.
\end{abstract}

European Journal of Endocrinology 155 609-614

\section{Introduction}

The $o b$ gene product, leptin (1), is mainly secreted by the adipose tissue and acts predominantly by binding to hypothalamic cells. Biological effects of leptin include the suppression of food intake and the increase of energy expenditure, and consequently, the regulation of body weight (2-5). Several studies have suggested that leptin also influences sexual progression through puberty (6-8). Impaired growth and pubertal delay have been observed in children with diabetes (9-11). Also, these children tend to develop obesity, even if they are treated with modern insulin therapy. The mechanism of weight and, particularly in girls, of fat gain has not yet been examined; however, there are suggestions of an association between weight gain and hyperinsulinemia, which is reflected by correlations with insulin dose or treatment regime (12). The soluble leptin receptor (sOB$\mathrm{R}$ ) is thought to be shedded from the leptin membrane receptor and acts as a potential modulator of leptin actions. As a molar excess of sOB-R over leptin suppressed leptin bioactivity in vitro, the interaction between sOB-R and leptin may be a causal factor in the pathogenesis of weight gain in vivo (13). Type 1 diabetes mellitus (T1DM) may lead to increased serum levels of the sOB-R, so far, by an unknown mechanism. The observed molar excess of sOB-R may contribute to leptin insensitivity in these patients, which supports weight gain and a decrease in energy consumption in catabolic conditions like the newly diagnosed T1DM (14). However, the detailed role of the leptin axis in pathogenesis of T1DM remains unclear. The aim of our study was to investigate whether or not the leptin axis is already disturbed at the manifestation of the 
T1DM and whether metabolic decompensation reflected by hyperglycemia, ketoacidosis, and increased free fatty acids may be associated with the sOB-R release from its membrane receptor.

\section{Subjects and methods}

\section{Patients and controls}

With the new onset T1DM, 25 children (aged 1.5-17.0 years) admitted to the hospitals in Erlangen and Leipzig, were investigated. Blood samples collected before the beginning of the insulin therapy $(n=25)$ were used for clinical chemistry analysis and hormone measurements. These results were compared with levels of the same parameters determined from serum samples received during the first $18 \mathrm{~h}$ (mean \pm s.D. $11.1 \pm 4.3 \mathrm{~h}, n=16$ ) and $92 \mathrm{~h}(47.5 \pm 22.5 \mathrm{~h}, n=14)$ after the beginning of the insulin therapy. All patients, or their parents, were asked for written informed consent and agreed to participate in the study after approval of the local Ethics Committee. Diagnosis for T1DM was made according to the World Health Organization criteria.

\section{Clinical examination}

In all patients, clinical and anthropometric data were recorded using a structured data-sheet during examination before beginning insulin therapy. Weight was measured with light underwear to the nearest of $0.1 \mathrm{~kg}$ on a calibrated balance beam scale. Height was measured to the nearest of $0.1 \mathrm{~cm}$ using a standardized measuring device (system Keller 2). Body mass index (BMI) was calculated as body weight (kg) divided by height $(\mathrm{m})$ squared. BMI-SDS levels were calculated according to the German Reference Data of KromeyerHausschild from 2002 (15). Pubertal development was assessed according to Tanner (16). Diagnosis of diabetic ketoacidosis was confirmed according to the recently published guidelines (17). The whole set of data is presented in Table 1.

\section{Biochemical analyses}

Blood samples were collected from a cubital vein between 0800 and $1200 \mathrm{~h}$. Samples were centrifuged at $4000 \mathrm{U}$ for $20 \mathrm{~min}$ and stored at $-25{ }^{\circ} \mathrm{C}$ until analysis. HbAlc was measured using the Tina-quant-aHbAlc technique of Boehringer Mannheim. Blood $\mathrm{pH}$, bicarbonate and therefore base excess were determined by the Rapidlab method (Bayer-Diagnostics, Munich, Germany). The automated AutoDELFIA method (Perkin-Elmer-Diagnostics, Brussels, Belgium) was used to analyze C-peptide levels with a sensitivity of $5 \mathrm{pmol} / \mathrm{l}$ and intra-/interassay coefficients of variation below $6.3 \%$. Free fatty acids were measured by a standard method from Roche.

\section{Serum parameter of the leptin axis}

Leptin was measured by a specific RIA (RIA, Mediagnost, Reutlingen, Germany). The sensitivity of the RIA was $0.04 \mathrm{ng} / \mathrm{ml}$. Intra- and interassay coefficients of variation were below $7.6 \%$.

sOB-R was measured with a ligand-immunofunctional assay (18). The lowest detectable sOB-R concentration in the assay was calculated to be less than $2 \mathrm{ng} / \mathrm{ml}$. Intra- and interassay coefficients of variation for two control samples were lower than $11.7 \%(n=10)$. The molar sOB-R/leptin ratio was calculated by the measured levels of sOB-R, divided by the leptin values, and multiplied with 0.123 as ratio of the molecular weights between both parameters (13).

\section{Statistical analysis}

For statistical analysis, we used the STATISTICA 6.0 software program. In the case of non-normally

Table 1 Descriptive data of the study group $(n=25)$.

\begin{tabular}{|c|c|c|c|}
\hline Parameter & Median & Range & Normal levels \\
\hline Age (years) & 10.0 & $0.9-17.0$ & \\
\hline Body mass index (BMI)-SDS & -0.55 & $(-5.74)-(+1.71)$ & $(-2)-(+2)$ \\
\hline Weight-SDS & 0.66 & $(-0.91)-(+3.88)$ & $(-2)-(+2)$ \\
\hline Height-SDS & -0.13 & $(-2.90)-(+2.00)$ & $(-2)-(+2)$ \\
\hline C-peptide (nmol/l) & 0.11 & $0.02-0.31$ & $0.12-1.19$ \\
\hline Blood glucose (mg/dl) & 436 & $191-882$ & $<100$ \\
\hline Free fatty acids & 1.48 & $0.37-4.42$ & $<0.6$ \\
\hline $\mathrm{pH}$ & 7.31 & $6.93-7.46$ & $7.36-7.44$ \\
\hline Base excess & -5.90 & $-25.0-0.9$ & \pm 2 \\
\hline Bicarbonate (mmol/l) & 18.0 & $6.20-24.2$ & $21-26$ \\
\hline Leptin $(\mathrm{ng} / \mathrm{ml})$ & 1.14 & $0.04-8.24$ & a \\
\hline Soluble leptin receptor (sOB-R) (ng/ml) & 196 & $59-393$ & $\mathrm{~b}$ \\
\hline sOB-R/leptin (molar ratio) & 12.0 & $1.35-1177$ & c \\
\hline
\end{tabular}

The following reference intervals cannot be shown in the table for the following reasons.

aLeptin levels are dependent on gender, age, and BMI. ${ }^{b}$ sOB-R levels are dependent on age and pubertal state. ${ }^{c} s O B-R / l e p t i n$ ratio is dependent on gender, age, BMI, and pubertal stage. 

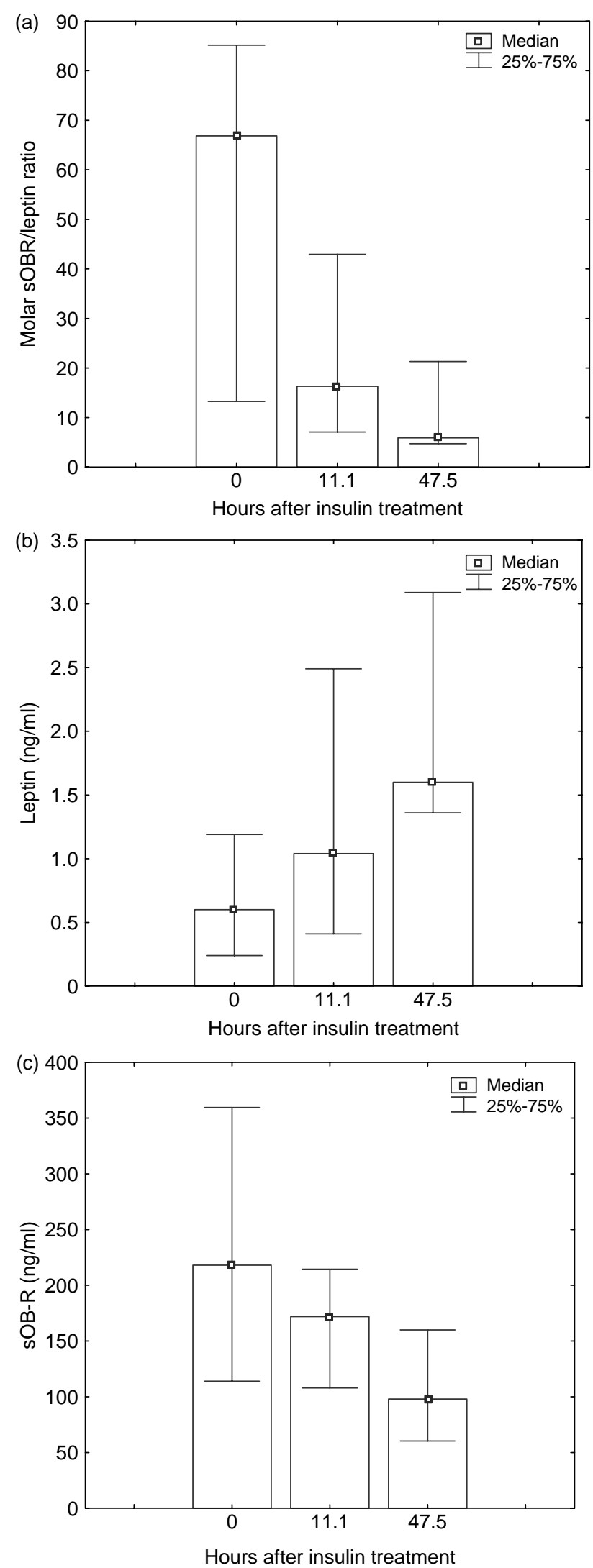

distributed data, nonparametric statistical tests were used for all statistical analyses including these parameters. Comparison between the blood levels of all parameters measured at different time points during the longitudinal study were performed by ANOVA as well as by post hoc Mann-Whitney U-test. Stepwise forward multiple regression analysis was used to estimate the prediction of variance for SOB-R by potential influencing factors.

\section{Results}

Patients demonstrated normal anthropometric parameters at diagnosis, but a decompensated metabolic state with hyperglycemia, glucosuria, ketonuria, acidosis and low C-peptide levels (Table 1). Leptin levels increased $(P<0.05)$, and sOB-R levels and sOB-R/leptin ratios decreased dramatically $(P<0.05)$ after starting the insulin therapy (Fig. $1 \mathrm{a}-\mathrm{c}$ ).

A positive correlation was calculated between basal serum sOB-R and blood glucose levels $(r=0.49 ; P<0.05)$. Additionally, highly significant correlations between sOB$\mathrm{R}$ and distinctive parameters of metabolic decompensation (Table 2), such as pH ( $r=-0.72$; Fig. 2), base excess $(r=-0.70)$, and bicarbonate levels $(r=-0.69)(P<$ $0.0001)$ at the diagnosis of T1DM also remained significant within the first $11.1 \mathrm{~h}$ of insulin treatment $(P<0.02$, data not shown). After a median time range of $47.5 \mathrm{~h}$ only the base excess remained significantly correlated with sOB-R $(P<0.05)$. On the contrary, at admission to the hospital, leptin levels were correlated with levels of free fatty acids, but were not associated with either BMI or glucose and parameters of metabolic decompensation. Only after $47.5 \mathrm{~h}$ of insulin therapy was a trend for the expected positive correlation between leptin and BMI-SDS calculated $(r=0.45 ; P=0.08)$. Multiple regression analysis with sOB-R as dependent and all variables of Table 2 as independent parameters revealed that base excess predicted $41.0 \%(P<0.001)$, age $16.4 \%(P<0.05)$, and height SDS $13.9 \%(P<0.01)$ of the sOB-R variance. A significant association between age and metabolic parameters was not observed.

\section{Discussion}

In this study, we demonstrated for the first time that metabolic decompensation in children with newly onset T1DM is associated with dramatic changes of the leptin

Figure 1 Changes of serum molar ratio of soluble leptin receptor (sOB-R) against leptin (a), levels of leptin (b) as well as levels of sOB-R (c) in patients with newly manifested type1 diabetes mellitus (T1DM) within the first $92 \mathrm{~h}$ of insulin treatment. Hormone levels are indicated as median and quartiles. First blood withdrawal was performed at the start of insulin therapy; second, $11.1 \pm 4.3 \mathrm{~h}$ (mean \pm S.D.) after starting insulin treatment (maximum $18 \mathrm{~h}$ ) and third, $47.5 \pm 22.5 \mathrm{~h}(n=12)$ 
Table 2 Coefficients of correlation $(r)$ of leptin and soluble leptin receptor (sOB-R) results from 25 children with newly manifested type 1 diabetes mellitus (T1DM).

\begin{tabular}{lcc}
\hline Parameter & $\begin{array}{c}\text { Parameter vs leptin } \\
\text { coefficient of } \\
\text { correlation } \boldsymbol{r}\end{array}$ & $\begin{array}{c}\text { Parameter vs sOB-R } \\
\text { coefficient of } \\
\text { correlation } \boldsymbol{r}\end{array}$ \\
\hline Gender & 0.34 & 0.24 \\
Age & -0.26 & -0.34 \\
Height-SDS & 0.16 & 0.21 \\
Weight-SDS & 0.20 & -0.04 \\
Body mass index & 0.15 & $-0.42^{*}$ \\
$\quad$ (BMI)-SDS & & -0.02 \\
HbAlc & 0.32 & $0.50^{\dagger}$ \\
Glucose & -0.40 & $-0.72^{\ddagger}$ \\
pH & 0.22 & $-0.70^{\ddagger}$ \\
Base excess & 0.20 & $-0.69^{\ddagger}$ \\
Bicarbonate & 0.20 & $0.55^{\dagger}$ \\
Free fatty acids & $-0.56^{\dagger}$ & -0.20 \\
C-Peptide & -0.29 & \\
\hline${ }^{*} P<0.05 \cdot{ }^{\dagger} P<0.01 ;{ }^{\ddagger} P<0.001$ & &
\end{tabular}

axis; serum levels of sOB-R are elevated and levels of leptin are reduced. Our finding that leptin levels are decreased at manifestation of T1DM may be explained by the insulin deficiency of our patients, demonstrated by hyperglycemia with low C-peptide levels and is supported by the literature (19-21). However, the observation that sOB-R levels associated with a decompensated metabolic state in our patients is new and suggests a leptin- and fat mass-independent regulation of the sOB-R secretion in T1DM. The pathophysiological regulation and the mechanism of this shedding process are not completely understood. A possible explanation for the increase of sOB-R observed in our patients may be the induction of the protein kinase $\mathrm{C}$ (PKC) activity in the diabetic state. PKC can induce A disintegrin and metalloprotease (ADAM) 17 (22), which is able to shed the extracellular domain of

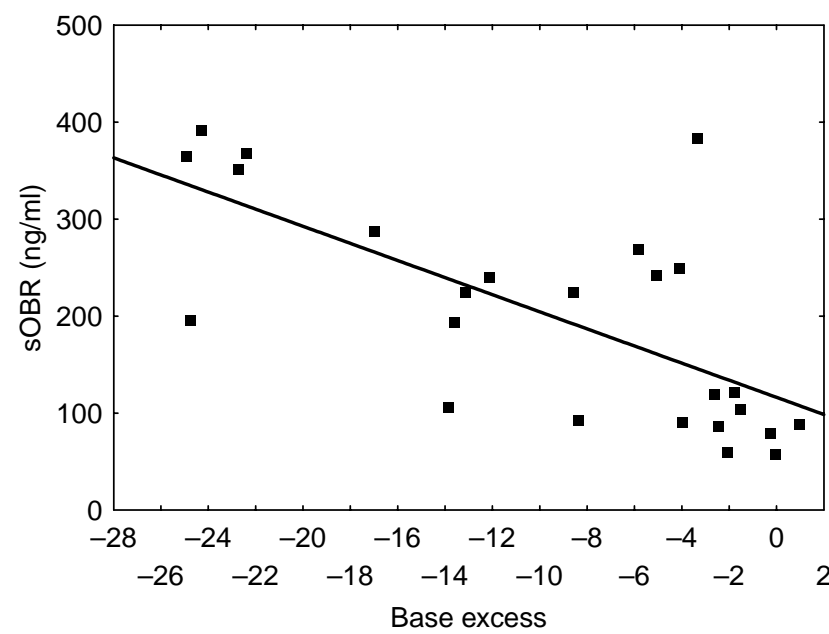

Figure 2 Correlation between serum soluble leptin receptor (sOB-R) level and base excess in patients with newly manifested type 1 diabetes mellitus before insulin treatment was started $(r=-0.70$, $P<0.001, n=25$ ). cytokine-like hormone receptors, such as the growth hormone-receptor and the OB-R, leading to increased levels of the soluble receptor. The fact that deficiency of substrates for the energy supply, such as lack of intracellular glucose in T1DM, leads to increased levels of circulating sOB-R is in agreement with previous data showing the same effect in conditions with weight loss, malnutrition, insulin treatment of T1DM with poor glycemic control, or nephrotic syndrome (14, 23-26). Furthermore, our data suggest that age, height-SDS, and parameters of metabolic decompensation have the strongest power for the prediction of sOB-R variance. Whereas age and height-SDS are well known for their impact on sOB-R levels (18), parameters such as blood glucose, $\mathrm{pH}$, bicarbonate, and base excess have not been described for their correlation with sOB-R data. However, as these parameters indirectly reflect the degree of the lack of substrates, the findings of this study are strongly supported by the above-mentioned studies. Interestingly, we were able to demonstrate that insulin treatment reverses the increased sOB-R levels of the patient in parallel with the improvement of its metabolic parameters within a couple of days. This finding suggests that the shedding process is also strongly associated with the degree of replenishing energy or substrate stores. In contrast, neither glucose nor levels of the parameters characterizing potential diabetic ketoacidosis were significantly correlated with serum leptin levels. We hypothesize, therefore, that the regulation of leptin and sOB-R may be independent from one another at manifestation of T1DM and during its treatment. This must not be the case in non-diabetic subjects, where leptin or fat mass differences may influence sOB-R serum levels $(27,28)$. The biological impact of increased sOB-R levels in newly diagnosed diabetes is presently unclear. Due to its binding affinity which is comparable to the binding affinity of the membrane leptin receptor $(29,30)$, the sOB-R may modulate leptin action in two ways: first, sOB-R could inhibit the binding of leptin to specific membrane receptors by its direct competition for the ligand. In a recent paper, our group was able to demonstrate that a tenfold molar excess of sOB-R over leptin distinctly suppressed leptin bioactivity in vitro (13). Up to 1000fold molar excess shown by this study has not been described in the literature so far. Thus, we hypothesize that this molar excess of sOB-R contributes to leptin insensitivity, which may support substrate uptake and a decrease of energy consumption in a catabolic state like newly diagnosed T1DM. Hyperphagia observed prior to, or shortly after, starting insulin substitution could be partly explained by the distinctive changes of the leptin axis $(31,32)$. Moreover, upregulation of the soluble leptin receptor appears to be a common mechanism to compensate substrate deficiency in energy deprivation states. The second explanation implicates that complexes of leptin and sOB-R may delay the renal clearance of the reduced leptin levels circulating at the 
manifestation of T1DM. By this mechanism, low leptin levels would be saved for the maintenance of essential neuroendocrine functions (33). Although we cannot definitely assess which of these mechanisms may be physiologically more important, both pathways could be involved in the process of favoring substrate delivery in energy deprivation states. Interestingly, if we assume that the liver is the main source of sOB-R (34), the dynamic changes in sOB-R levels could be used as an indicator for hepatic substrate availability and, therefore, for the control and optimization of insulin treatment in T1DM as well as for the supply of substrate in other catabolic conditions. In conclusion, the finding of elevated sOB-R levels in children and adolescents with diabetes extends circuitry between body weight control and appetite regulation under physiological and pathophysiological conditions. Most interestingly, the question of whether or not patients with potential leptin insensitivity may have a better chance to overcome a state of metabolic decompensation in T1DM should be a goal for further clinical studies.

\section{Acknowledgements}

The authors are very grateful to Mrs Jaeschke and Mrs Liebig for the excellent technical assistance. This work was supported by the Bundesministerium für Bildung und Forschung $(\mathrm{BMB}+\mathrm{F})$, Interdisciplinary Centre for Clinical Research (IZKF) at the University of Leipzig (Project B15), Leipzig, Germany.

\section{References}

1 Zhang Y, Proenca R, Maffei M, Barone M, Leopold L \& Friedmann JM. Positional cloning of the mouse obese gene and its human homologue. Nature 1994372 425-432.

2 Pelleymounter MA, Cullen MJ, Baker MB, Hecht R, Winters D, Boone T \& Collins F. Effects of obese gene product on body weight regulation in ob/ob mice. Science $1995269540-543$.

3 Halaas JL, Gajiwala KS, Maffei M, Cohen SL, Chait BT, Rabinowitz D, Lallone RL, Burley SK \& Friedman JM. Weight reducing effects of the plasma protein encoded by the obese gene. Science $1995269543-546$.

4 Campfield LA, Smith FJ, Guisez Y, Devos R \& Burn P. Recombinant mouse $\mathrm{OB}$ protein: evidence for a peripheral signal linking adiposity and central neural networks. Science $1995 \mathbf{2 6 9} 546-549$.

5 Stephens TW, Basinski M, Bristow PK, Bue-Valleskey JM, Burgett SG, Craft L, Hale J, Hoffman J, Hsiung HM, Kriauciunas A, MacKellar W, Rosteck PR, Schoner B, Smith D, Tinsley FC, Zhang XY \& Heimann M. The role of neuropeptide $\mathrm{Y}$ in the antiobesity action of the obese gene product. Nature 1995377 530-532.

6 Clayton PE, Gill MS, Hall CM, Tillmann V, Whatmore A \& Price DA. Serum leptin through childhood and adolescence. Clinical Endocrinology $1997 \mathbf{4 6} 727-733$.

7 Friedman JM \& Halaas JL. Leptin and the regulation of body weight in mammals. Nature 1998395 763-770.

8 Kiess W, Reich A, Meyer K, Glasow A, Deutscher J, Klammt J, Yang Y, Müller G \& Kratzsch J. A role for leptin in sexual maturation and puberty. Hormone Research 199951 55-63.

9 Thon A, Heinze E, Feilen KD, Holl RW, Schmidt H, Koletzko S, Wendel U \& Nothjunge J. Development of height and weight in children with diabetes mellitus: report on two prospective multicentre studies, one cross-sectional, one longitudinal. European Journal of Pediatrics $1992151258-262$.

10 Brown M, Ahmed ML, Clayton KL \& Dunger DB. Growth during childhood and final height in type 1 diabetes. Diabetic Medicine 199411 182-187.

11 Luna R, Garcia-Mayor RV, Lage M, Andrade MA, Barreiro J, Pmobo M, Dieguez C \& Casanueva FF. High serum leptin levels in children with type 1 diabetes mellitus: contribution of age, BMI, pubertal development and metabolic status. Clinical Endocrinology $199951603-610$.

12 Dunger DB, Ahmed ML \& Ong KKL. Growth and body composition in type 1 diabetes mellitus. Hormone Research 200258 (suppl 1) 66-71.

13 Zastrow O, Seidel B, Kiess W, Thiery J, Keller E, Böttner A \& Kratzsch J. The soluble leptin receptor is crucial for leptin action: evidence from clinical and experimental data. International Journal of Obesity 200327 1472-1478.

14 Kratzsch J, Deimel A, Galler A, Kapellen T, Klinghammer A \& Kiess W. Increased serum soluble leptin receptor levels in children and adolescents with type1 diabetes mellitus. European Journal of Endocrinology $2004151415-529$.

15 Kromeyer-Hauschild K, Wabitsch M, Kunze D, Geller F, Geiß HC, Hesse V, von Hippel A, Jaeger U, Johnsen D, Korte W, Menner K, Müller G, Müller JM, Niemann-Pilatus A, Remer T, Schaefer F, Wittchen HU, Zabransky S, Zellner K, Ziegler A \& Hebebrand J. Perzentilen für den body-mass-index für das Kindes-und Jugendalter unter Heranziehung verschiedener deutscher Stichproben. Monatsschrift Kinderheilkunde 2001149 807-818.

16 Tanner JM. Growth at Adolescence. 2nd edn. Oxford: Blackwell Scientific, 1962.

17 Dunger DB, Sperling MA, Acerini CL, Bohn DJ, Daneman D, Danne TP, Glaser NS, Hanas R, Hintz RL, Levitsky LL, Savage MO, Tasker RC \& Wolfsdorf J. European Society for Paediatric Endocrinology; Lawson Wilkins pediatric endocrine society. European society for paediatric endocrinology/Lawson Wilkins pediatric endocrine society consensus statement on diabetic ketoacidosis in children and adolescents. Pediatrics 2004113 e133-e140.

18 Kratzsch J, Lammert A, Böttner A, Seidel B, Mueller G, Thiery J, Hebebrand W \& Kiess W. Circulating soluble leptin receptor and free leptin index during childhood, puberty, and adolescence. Journal of Clinical Endocrinology and Metabolism 200287 4587-4594.

19 Soriano-Guillen L, Barrios V, Lechuga-Sancho A, Chowen JA \& Argente J. Response of circulating ghrelin levels to insulin therapy in children with newly diagnosed type 1 diabetes mellitus. Pediatric Research 200455 830-835.

20 Hanaki K, Becker DJ \& Arslanian SA. Leptin before and after insulin therapy in children with new-onset type 1 diabetes. Journal of Clinical Endocrinology and Metabolism 199984 1524-1526.

21 Hathout EH, Sharkey J, Racine M, Ahn D, Mace JW \& Saad MF. Changes in plasma leptin during the treatment of diabetic ketoacidosis. Journal of Clinical Endocrinology and Metabolism $1999844545-4548$.

22 Zhang Y, Jiang J, Black RA, Baumann G \& Frank SJ. Tumor necrosis factor-alpha converting enzyme (TACE) is a growth hormone binding protein (GHBP) sheddase: the metalloprotease TACE/ADAM-17 is critical for (PMA-induced) GH receptor proteolysis and GHBP generation. Endocrinology $20001414342-4348$.

23 Reinehr T, Kratzsch J, Kiess W \& Andler W. Circulating soluble leptin receptor, leptin, and insulin resistance before and after weight loss in obese children. International Journal of Obesity 2005 29 1230-1235.

24 Kratzsch J, Schubring C, Stitzel B, Bottner A, Berthold A, Thiery J \& Kiess W. Inverse changes in the serum levels of the soluble leptin receptor and leptin in neonates: relations to anthropometric data. Journal of Clinical Endocrinology and Metabolism 200590 2212-2217.

25 Stein K, Vasquez-Garibay E, Kratzsch J, Romero-Velarde E \& Jahreis G. Influence of nutritional recovery on the leptin axis in severely malnourished children. Journal of Clinical Endocrinology and Metabolism 200691 1021-1026. 
26 Schroth M, Kratzsch J, Groschl M, Rauh M, Rascher W \& Dotsch J. Increased soluble leptin receptor in children with nephrotic syndrome. Journal of Clinical Endocrinology and Metabolism 2003 88 5497-5501.

27 Ogier V, Ziegler O, Mejean L, Nicolas JP \& Stricker-Krongrad A. Obesity is associated with decreasing levels of the circulating soluble leptin receptor in humans. International Journal of Obesity and Related Metabolic Disorders 200226 496-503.

28 Monteleone P, Fabrazzo M, Tortorella A, Fuschino A \& Maj M. Opposite modifications in circulating leptin and soluble leptin receptor across the eating disorder spectrum. Molecular Psychiatry 20027 641-646.

29 Lammert A, Kiess W, Böttner A, Glasow A \& Kratzsch J. Soluble leptin receptor represents the main leptin binding activity in human blood. Biochemical and Biophysical Research Communications $2001283982-988$.

30 Liu C, Liu XJ, Barry G, Ling N, Maki R \& DeSouza EB. Expression and characterization of a putative high affinity human soluble receptor. Endocrinology 1997138 3548-3554.
31 Sindelar DK, Havel PJ, Seeley RJ, Wilkinson CW, Woods SC \& Schwartz MW. Low plasma leptin levels contribute to diabetic hyperphagia in rats. Diabetes 1999148 1275-1280.

32 Wing RR, Nowalk MP, Marcus MD, Koeske R \& Finegold D. Subclinical eating disorders and glycemic control in adolescents with type I diabetes. Diabetes Care 19869 162-167.

33 Chan JL \& Mantzoros CS. Role of leptin in energy-deprivation states: normal human physiology and clinical implications for hypothalamic amenorrhoea and anorexia nervosa. Lancet 2005 $36674-85$.

34 Cohen P, Yang G, Yu X, Soukas AA, Wolfish CS, Friedman JM \& $\mathrm{Li} \mathrm{C}$. Induction of leptin receptor expression in the liver by leptin and food deprivation. Journal of Biological Chemistry $20052 \mathbf{2 8 0}$ 10034-10039.

Received 4 April 2006

Accepted 18 July 2006 